\title{
$\simeq$
}

\section{Understanding the Process and Conditions That Improve Preservice Teachers' Conceptions of Nature of Science in Real Contexts}

\section{Bianor Valente, Paulo Maurício \& Cláudia Faria}

To cite this article: Bianor Valente, Paulo Maurício \& Cláudia Faria (2018) Understanding the Process and Conditions That Improve Preservice Teachers' Conceptions of Nature of Science in Real Contexts, Journal of Science Teacher Education, 29:7, 620-643, DOI: 10.1080/1046560X.2018.1485399

To link to this article: https://doi.org/10.1080/1046560X.2018.1485399

\section{Published online: 12 Jul 2018.}

Submit your article to this journal ¿

Џll Article views: 205

Q View related articles $\sqsubset$

View Crossmark data $\nearrow$ 


\title{
Understanding the Process and Conditions That Improve Preservice Teachers' Conceptions of Nature of Science in Real Contexts
}

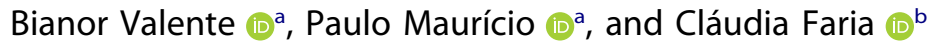 \\ aEscola Superior de Educação de Lisboa, Instituto Politécnico de Lisboa, Campus de Benfica, Lisboa, Portugal; \\ bInstituto de Educação, Universidade de Lisboa, Alameda da Universidade, Lisboa, Portugal
}

\begin{abstract}
The present study conceptualized, implemented, and evaluated a specific program, the Live Science program. This program integrated 2 distinct but complementary approaches: participants' immersion in real science contexts and the participation of future teachers in seminars intended to share the immersion experience and to reflect on nature of science (NOS). Four future teachers participated in the Live Science program in 2 real research contexts. Through an analysis of the experiences and lessons learned from this program, this study tried to understand to what extent participation in real-context scientific activities, focused on an explicit and reflective approach to NOS, can contribute to the professional development of preservice elementary teachers. Interviews, questionnaires, observations, diaries, and videotaped seminars were used for data collection. Our findings suggest that the adoption of an explicit approach through illustration and reflection on particular aspects of NOS within the context of scientific research is a promising approach considering that it potentially allows for the development of a more informed understanding of science. The results also suggest that along with personalityrelated factors, the inherent characteristics of real science contexts play an important role in the development of that understanding. Tightly organized research teams capable of giving ample support to preservice teachers and working in research fields in which participants' conceptions can be confronted should be selected in order to improve the impact of this type of program.
\end{abstract}

\section{KEYWORDS}

nature of science; preservice elementary teacher training; science apprenticeship; scientific literacy

Nature of science (NOS) has long been recognized as a structuring dimension of scientific literacy (Bybee, 1997; Hodson, 2009; Matthews, 2012) and has been advocated as a critical educational outcome in different science education reform documents (American Association for the Advancement of Science, 1993; Ministry of Education, 2007; National Research Council, 1996; NGSS Lead States, 2013). Broadly, NOS is a term used for the "description of what science is, how it works, how scientists operate as a social group and how society itself both directs and reacts to scientific endeavours" (McComas, Clough, \& Almazroa, 1998, p. 4).

Lederman (2004), while acknowledging that there is no consensus among philosophers, historians, and science educators about a specific definition of NOS, argued that when the debate is confined to aspects of NOS that should be incorporated into science education, 
some consensus emerges. According to this author, three criteria must precede the selection of NOS features to work with students, namely, accessibility to all students, consensus, and usefulness of the NOS aspect. Based on these criteria, seven NOS aspects were identified as relevant in the context of science education (Lederman, Abd-El-Khalick, Bell, \& Schwartz, 2002): (a) the tentative nature of scientific knowledge, because although it is reliable and durable, it is never absolute or certain; (b) the empirical nature of scientific knowledge, as science is at least partially based on observations of the natural world; (c) the theory-laden nature of scientific knowledge, because scientists' prior knowledge, epistemic and ontological beliefs, and cultural background affect the outcome of their work; (d) the creativity and imagination present in the scientific enterprise, as it is done by scientists involved in the creation of new solutions or explanations; (e) the influence of cultural and social elements on the scientific knowledge since scientists are immersed in a social milieu that determines to some extent their work; $(f)$ the fact that laws are statements that describe the relationships between observable phenomena, and theories by contrast are inferred explanations of those phenomena; $(\mathrm{g})$ the myth of the scientific method, as no single scientific method exists.

However, the conceptualization of the construct is far from consensual. Recent trends regarding thinking about NOS have generated discussions about the scope of the concept, in particular regarding the different dimensions it encompasses (epistemological, methodological, ontological), the generality of NOS understandings (domain general vs. domain specific), and in some cases considerations regarding the construct designation itself (Allchin, 2011, 2013; Clough, 2006; Hodson, 2008, 2009, 2014; Irzik \& Nola, 2011; Matthews, 2012). Despite recognizing the importance of these arguments in defining what constitutes NOS, we like other authors claim that regarding science education, the domain-general, consensus-based approach is a pragmatic and effective way to introduce NOS (Abd-El-Khalick, 2012; Kampourakis, 2016; Lederman \& Lederman, 2014).

Although the relevance of learning about NOS is consensual in the literature, various investigations have shown that teachers and students at different levels of schooling have inadequate views regarding NOS (Lederman, 2007). This finding is identical for prospective elementary teachers, the focus of our study. For example, a study conducted by Abell and Smith (1994) with 140 preservice elementary teachers showed that students have realist and positivist views of science. Moreover, Murcia and Schibeci (1999) identified several naive views about NOS after analyzing the conceptions held by 73 preservice elementary teachers. In a study involving 50 preservice elementary teachers Akerson, AbdEl-Khalick, and Lederman (2000) also found that the majority of the participants held, at the beginning of the investigation, naive views of one or more of the seven NOS aspects analyzed. More recently, Abd-El-Khalick and Akerson (2004) found that the great majority of the 28 preservice elementary teachers involved in their study expressed naive views of NOS. Liang et al. (2009) studied 640 preservice teachers from the United States, China, and Turkey and, in addition to identifying different patterns across the three countries, identified the general misunderstandings found in the other studies.

Nowadays the relations between teachers' conceptions, their practices, and students' conceptions are no longer regarded linearly, as even when teachers have conceptions in line with the literature, this knowledge is not necessarily transferred to the classroom (Bell, Lederman, \& Abd-El-Khalick, 2000; Lederman, 2007; McComas et al., 1998; Wahbeh \& Abd-El-Khalick, 
2013). Even so, teachers' informed views of NOS are still a necessary condition to foster students' conceptions of science. Therefore, the fact that future teachers hold inadequate conceptions of NOS constitutes an obstacle to achieving the goals expressed by the science education community.

Several approaches have been explored in teacher training programs and with inservice teachers to improve NOS understandings. The active participation of (future) teachers in scientific activities in real contexts of science has been one of the alternative approaches adopted and investigated in some countries. This training model is inspired by the apprenticeship, an approach in which newcomers interact and work in close contact with old timers in order to learn a trade through a combination of observation, coaching, and practice. This approach is based on sociocultural perspectives on learning that suggest that knowledge is highly contextualized and related to the situations in which it occurs. Situated learning assumes that knowledge should be presented in authentic contexts and that learning requires social interaction and collaboration (Lave \& Wenger, 1991). The notion of legitimate peripheral participation, a "descriptor of engagement in social practice that entails learning as an integral constituent" (Lave \& Wenger, 1991, p. 35), is a central aspect of this perspective and should be regarded as an analytical perspective of learning and a way to understand it.

The trajectories of (future) teachers in scientific communities, especially when immersion time is limited, never lead to full participation and therefore fall into the category of peripheral trajectories (Wenger, 1998). Even so, these trajectories can provide a type of access to the community and its practice that may become significant enough.

The main assumption of these programs is that this experience can have profound impacts on the conceptions and practices of these professionals. Although a reasonable assumption, it requires, of course, empirical evidence that supports it. For this reason, it is essential to analyze studies that investigate the effects of these programs on (future) teachers' learning.

Among the benefits of these apprenticeship opportunities are the development of greater self-confidence and motivation (Dresner \& Worley, 2006; Melear, Goodlaxson, Warne, \& Hickok, 2000), the learning of scientific content (Brown \& Melear, 2007), and the promotion of teacher-teacher and teacher-scientist collaborations (Dresner \& Worley, 2006; Raphael, Tobias, \& Greenberg, 1999; Westerlund, García, Koke, Taylor, \& Mason, 2002). Regarding the impact of these programs on teachers' conceptions of NOS, changes have been documented, namely, ideas concerning time and persistence associated with the collection of scientific data as well as the complexity of scientific research (Varelas, House, \& Wenzel, 2005). However, changes regarding more complex aspects of NOS were only detected when an explicit NOS approach was adopted (Hughes, Molyneaux, \& Dixon, 2012; Schwartz, Lederman, \& Crawford, 2004; Schwartz, Northcutt, Mesci, \& Stapleton, 2013; Schwartz, Westerlund, García, \& Taylor, 2010).

Despite the growing literature on this subject, there are still several issues that require further investigation. Sadler, Burgin, McKinney, and Ponjuan (2010) highlighted the importance of conducting studies with greater methodological diversity and adopting instruments to assess more directly the impact of these programs. According to these authors, understanding the impact of particular and singular features of these apprenticeships on promoting or inhibiting the learning of (future) teachers will allow for an adequate conceptualization of these programs. 
In light of these suggestions, we conducted a study to explore the impact of research experiences in real science contexts, offered in the Live Science program, on preservice elementary teachers, a population that is not typically involved in this kind of apprenticeship. This study intended to analyze the development arising from the singularities of this program, especially concerning views of NOS, and to understand the process as well as the conditions that promoted it. Specifically, this study focused on the following research questions: (a) What are the features of the research experiences offered in the Live Science program? (b) How do preservice elementary teachers' views of NOS change during the Live Science program? (c) What features of the program, if any, are more relevant for fostering NOS understandings?

\section{Methodology}

\section{Live Science program}

One of the main goals of the Live Science program was to immerse preservice elementary teachers in real scientific contexts for 3 weeks. Two different research projects in two different areas (biology and geology) were offered. The performance of analogue and numerical modeling experiments to study the tectonic interference between geological faults was the main goal of the geology project. Analogue modeling is a technique in which artificial/laboratory materials are used to simulate the mechanical deformation of rocks in nature. The other research experience was related to the development of new antimalarial drugs through an in vivo approach. An analysis of the antimalarial activity of different compounds was conducted using rodent models and involved assessing the transmission-blocking activity of the parasite in mosquitoes. The scientists in charge of these investigations were asked to discuss the research goals, as well as the context and the underlying techniques, with the participants. It was also requested that preservice teachers be involved in the different stages of the investigation.

Besides the immersion in real scientific contexts, this program also comprised five seminars. The main goal of the first seminar was to describe the research settings as well as participants' first reactions and impressions. The other four seminars were dedicated to different NOS dimensions. In these seminars different strategies were implemented to foster collaborative and shared reflection: (a) reading responses from the initial questionnaire (see "Data Collection") in order to make participants' initial conceptions visible to all, (b) engaging in comparative analysis of the answers, (c) freely searching elements/ experienced situations that enabled reinterpretation of the NOS aspects in question, and (d) reading cases selected by the researchers to illustrate and contextualize NOS in the apprenticeship.

\section{Participants}

A total of four preservice elementary teachers and two scientists participated voluntarily in this study. Pseudonyms are used to refer to all of the participants involved. The two scientists, Frederico and Diana, were selected based on their previous experience in terms of collaborative work with students and teachers. The four preservice elementary teachers held a bachelor's in basic education (a generalist 3-year bachelor's degree that does not 
confer professional qualifications) and were enrolled in the last year of a 2-year master's program in a Portuguese School of Education aimed at elementary teacher training. Whereas Helena and João collaborated with Frederico and were involved in analogue and numerical modeling experiments to investigate the tectonic interference between faults, Leonor and Carla collaborated with Diana in the development of new antimalarial drugs by testing compounds for activity against malaria parasite development in the mosquito vector.

\section{Data collection}

Before the Live Science program, a questionnaire was administered to assess the preservice teachers' initial conceptions of NOS. The questionnaire (Q1) included nine questions adapted from the Views of Nature of Science Form C (Abd-El-Khalick \& Lederman, 2000). Follow-up interviews (Q1fu) were conducted to clarify these answers.

During the apprenticeship, participants created an electronic laboratory notebook in which the research activities, as well as reflections on the collaboration experience and the environment, were recorded. Unstructured observations and interviews were made by the first author to provide a richer and more direct report of the apprenticeship. Immediately before the seminar some of the answers given on the Q1 (those related to NOS aspects that were going to be analyzed in the seminar) were devolved to each participant. Participants were requested to reanswer if the text did not reflect their current idea (Q2). All reflective seminars were videotaped and transcribed.

After the program final interviews (FIs) were conducted in order to gain insight into participants' views about the Live Science program and to obtain information about the perceived learning outcomes and the respective sources. During these interviews we returned once again the Q1 questionnaire and asked whether each participant would like to change (or not) a given answer and why (Q3). A list of the text corpus is presented in Figure 1, as are the codes used to identify the data sources.

\section{Data analysis}

All of the text corpus was word-processed and entered into NVivo, a qualitative data analysis software program. The data analysis and interpretation was performed by the first

\section{Research field notes (FN) \\ Laboratory notebook (LB)}

\section{"Doing Science" (3 weeks)}

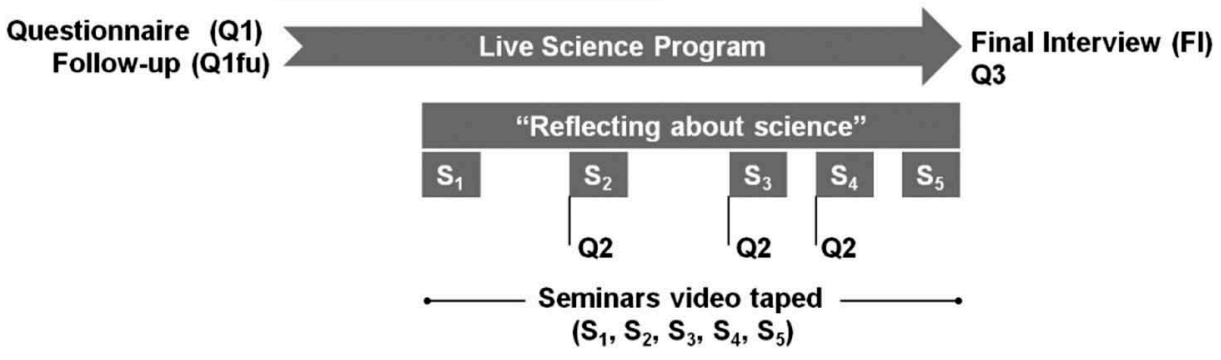

Figure 1. Instruments used and respective codes. 
author with the support of this software, which made the analytical process more flexible and transparent. Indeed, the complete NVivo project provided an audit trail of the work done with records of the development of the data analysis through memoing. The second and third authors reviewed all of the analyses and interpretations, and results were discussed until consensus was reached. Moreover, to increase trustworthiness and credibility, all interpretations were triangulated with data collected from multiple methods, as shown in Figure 1, and member checking was performed (Creswell, 2007; Denzin \& Lincoln, 1994; Merriam, 1995).

\section{Research experiences}

The data analysis regarding the research experiences was influenced by the grounded theory approach (Corbin \& Strauss, 2008). Using the constant comparison method of analysis, data from the first author's field notes, participants' notebooks, seminar transcripts and final interviews were triangulated. Through open coding, recurring themes and events were identified. Then axial coding was used to group and label these themes and events into categories. In the final stage, all categories were collapsed into the following dimensions: (a) affective-relational (description of the social context of the apprenticeship as well as how the participants perceived this context), (b) epistemic (encompassing categories that allowed us to analyze the extent to which the participants were conceptually involved in the investigation, such as the help and support provided by the research team, participants' behavior, difficulties understanding the concepts and phenomena under study), and (c) methodological (the level of autonomy in technical tasks, including preparation/assembly of the experiments, data collection, etc., and the support given by the group to help participants perform these procedures). The process of reorganizing and creating broader categories was a combination of data-driven and theory-driven strategies. For example, in the literature, some authors (Bell, Blair, Crawford, \& Lederman, 2003) suggest that epistemic involvement is an aspect intertwined with the development of informed views of NOS. Therefore, all descriptive categories that revealed the role played by the participants regarding the formulation of research questions, research design, and interpretation of results, as well as the conceptual support and epistemic interactions within the research team, were collapsed into the epistemic dimension. Using these dimensions we compared both apprenticeships to identify the major differences and similarities between them with the ultimate goal of finding aspects of each experience that might have been responsible for the evolution of the NOS views held by the participants.

\section{NOS conceptions}

We organized data taking into account the NOS dimensions defined a priori based on our theoretical orientation. Six different NOS features were analyzed (tentativeness, creativity, subjectivity and theory-laden nature, functions and relations of theory and laws, social and cultural embeddedness, empirical nature of scientific knowledge). The description and interpretation of the data was done through the construction of individual profiles for each participant during the program.

The initial profiles (preprogram) were constructed from Q1 and Q1fu, the postapprenticeship and preseminar were derived from Q2, and the final profiles were obtained from the FI 
(postprogram). Then we coded the participants' views (after, during, and before the program) of each NOS aspect as either naive $(--)$, limited $(-)$, partially informed $(+)$, or informed (++) using an adapted coding scheme developed by McDonald (2008). In this study, a participant's view was coded as naive or limited if it was completely inconsistent with what the literature identifies as an adequate conception or substantial improvements were needed, respectively. Conversely, understandings were categorized as informed or partially informed if they represented the desired views or, although in line with contemporary reform statements, would benefit from developments, respectively. In Table 1 the definitions of each of the four categories of social and cultural influence are displayed alongside excerpts from participants' responses coded as naïve, limited, partially informed, and informed.

\section{Results and interpretation}

\section{Research experiences}

We found differences and commonalities between the geology and biology apprenticeships regarding three dimensions: (a) affective-relational, (b) epistemic, and (c) methodological (see Table 2).

Table 1. Category definitions and excerpts from participants' responses regarding the social and cultural embeddedness of scientific knowledge.

\begin{tabular}{|c|c|c|c|c|}
\hline $\begin{array}{l}\text { NOS coding } \\
\text { scheme }\end{array}$ & Naïve view & Limited view & Partially informed view & Informed view \\
\hline $\begin{array}{l}\text { Category } \\
\text { definition }\end{array}$ & $\begin{array}{l}\text { Explores the influence } \\
\text { of a science content } \\
\text { course incorporating } \\
\text { explicit nature of } \\
\text { science and } \\
\text { argumentation } \\
\text { instruction on } \\
\text { preservice primary } \\
\text { teachers' views of } \\
\text { nature of science. }\end{array}$ & $\begin{array}{l}\text { Recognizes the influence } \\
\text { of social and cultural } \\
\text { factors but implies that } \\
\text { these influences are } \\
\text { negative. }\end{array}$ & $\begin{array}{l}\text { Recognizes influences of } \\
\text { political, economic, and } \\
\text { ethical issues on what } \\
\text { scientists investigate. } \\
\text { Social and cultural } \\
\text { factors may influence } \\
\text { the rate at which } \\
\text { scientific truths are } \\
\text { recognized. }\end{array}$ & $\begin{array}{l}\text { Science as a human } \\
\text { enterprise is practiced in } \\
\text { the context of a larger } \\
\text { culture, and its } \\
\text { practitioners (scientists) are } \\
\text { the product of that culture. } \\
\text { Science, it follows, affects } \\
\text { and is affected by the } \\
\text { various elements and } \\
\text { intellectual spheres of the } \\
\text { culture in which it is } \\
\text { embedded. These elements } \\
\text { include, but are not limited } \\
\text { to, social fabric, power } \\
\text { structures, politics, } \\
\text { socioeconomic factors, } \\
\text { philosophy, and religion. } \\
\text { Provides adequate } \\
\text { examples. Recognizes } \\
\text { social and cultural } \\
\text { influences on how science } \\
\text { is practiced. }\end{array}$ \\
\hline $\begin{array}{l}\text { Sample } \\
\text { excerpt }\end{array}$ & $\begin{array}{l}\text { "I believe that science } \\
\text { is universal, trying not } \\
\text { to be influenced by } \\
\text { religious, cultural, etc. } \\
\text { values, since its } \\
\text { objective is to obtain } \\
\text { reliable answers." } \\
\text { (Helena, Q1) }\end{array}$ & $\begin{array}{l}\text { "I remember this } \\
\text { economic question, and } \\
\text { indeed science is not } \\
\text { above it but it should, } \\
\text { science is not made } \\
\text { without money, it is } \\
\text { necessary financially and } \\
\text { only finances what it is if } \\
\text { it thinks that it gives } \\
\text { profit." (Helena, Q3) }\end{array}$ & $\begin{array}{l}\text { "I think that science } \\
\text { reflects cultural and } \\
\text { social values, because } \\
\text { science answers } \\
\text { questions made by the } \\
\text { society, made by } \\
\text { someone that wants to } \\
\text { know more, and that } \\
\text { someone is not a } \\
\text { universal human being, } \\
\text { is a human being who is } \\
\text { involved in a society." } \\
\text { (João, Q1) }\end{array}$ & $\begin{array}{l}\text { "I think that everyone is } \\
\text { against the use of animals } \\
\text { to do experiences, but in } \\
\text { mice nobody cares, or at } \\
\text { least I have not seen } \\
\text { anyone criticizing for being } \\
\text { rats, if they were dogs... } \\
\text { so it reflects cultural values, } \\
\text { and in this case also social } \\
\text { values." (Leonor, Q3) }\end{array}$ \\
\hline
\end{tabular}

Note. Q1 = initial questionnaire; Q3 = final questionnaire. 
Table 2. Differences and commonalities between the geology and biology apprenticeships.

\begin{tabular}{|c|c|c|}
\hline Dimension & Geology & Biology \\
\hline \multirow[t]{2}{*}{$\begin{array}{l}\text { Affective- } \\
\text { relational }\end{array}$} & \multicolumn{2}{|c|}{$\begin{array}{l}\text { Positive, inclusive, and participatory environment } \\
\text { (personal and professional characteristics of the scientist and } \\
\text { research team) }\end{array}$} \\
\hline & $\begin{array}{l}\text { Huge number of interactions } \\
\text { (Scientist }+4 \text { geology students) }\end{array}$ & $\begin{array}{l}\text { Small number of interactions } \\
\text { (Scientist }+1 \text { doctoral student }+2 \text { technicians) }\end{array}$ \\
\hline \multirow[t]{4}{*}{ Epistemic } & \multicolumn{2}{|c|}{$\begin{array}{l}\text { Participants were immersed in a real investigation (not adopted) } \\
\text { Participants had no control over the research }\end{array}$} \\
\hline & Scientist efforts during all phases of the research & $\begin{array}{l}\text { Scientist effort during the initial phase of the } \\
\text { research }\end{array}$ \\
\hline & $\begin{array}{l}\text { Debates, discussion of ideas and controversies in } \\
\text { the geology field (scientist - geology students) }\end{array}$ & No debates and discussions \\
\hline & More conceptual difficulties & Fewer conceptual difficulties \\
\hline \multirow[t]{2}{*}{ Methodological } & \multicolumn{2}{|c|}{ Participants actively engaged in different procedures } \\
\hline & No difficulties & Difficulties \\
\hline
\end{tabular}

\section{Affective-relational environment}

The malaria research group constituted Diana (the group leader), Maria (a doctoral student), and two technicians. The number of interactions between the different elements of the team was, during the participants' collaboration, relatively low because not all members were working in the same facilities. In the geology group, besides the scientist, the participants also had the opportunity to interact with geology students who were also collaborating on the project. With few exceptions, all members of the group worked together in the same laboratory. Therefore, regarding group structure, we found differences between the two apprenticeships, with a higher number of interactions in the geology setting.

The environment in the geology apprenticeship was described by the participants as quite positive. Over time, the references to the environment were always positive, as this assessment was closely linked to the personal and professional characteristics of the scientist, namely, the fact that he was a person "very relaxed, available to teach ... available to learn from students, available to hear" (João, FI). The perception of these future teachers of the scientist's attitude toward their participation in the research project also contributed to the development of a sense of belonging. According to Helena, the research team members "made us feel not only part of the group, but an important part of it, considering that our presence would be beneficial to the project" (electronic laboratory notebook). Furthermore, the effort made by the scientist to foster communication and interaction within the group was also regarded as a positive aspect: "I always felt very comfortable, and I wasn't afraid to participate, because the scientist made us feel free to do it, and he asked us things and all" (Helena, FI).

The environment in the malaria apprenticeship was also described positively by the participants and, once again, the personal and professional characteristics of the elements of the research group were the most important aspects that helped to build a comfortable atmosphere. For example, according to Leonor, "I felt very well, they were so nice, and let us feel completely at home ... so I felt like I was here at the School of Education" (FI). Carla, despite her low expectations, was also surprised: "I had the idea that I will go there and I will disturb, but I felt that they were always super available" (FI). 


\section{Epistemic involvement}

In both places, participants had the opportunity to collaborate on a real scientific research project. The fact that these were authentic studies, predefined by the scientists, meant that none of the participants had an active role in the formulation of research questions or selection of methodology and materials, among other things.

Although in both places efforts were made to involve the participants conceptually, the frequency and the nature of the support provided by the research team was not the same. At the beginning of the malaria apprenticeship, the scientist tried to explain the goals of the experiments and clarified some concepts relevant to the pursuit of activities. During the remaining phases of the research, the conceptual support provided by the team was very little, with much of the attention focused on practical aspects, such as microscopy techniques and animal handling. In the geology apprenticeship, the scientist made several efforts to engage the participants epistemically, first through a description of the context that triggered the interest in the research topic and second through an explanation of the specific objectives of each experiment. During the various stages of the work, different members of the research team helped the participants to understand language and terminology by using more colloquial language to explain key geological terms and ideas. The geology students played a pivotal role in the mediation and appropriateness of this language: "At a certain point Frederico explains what are normal and reverse faults. Then, the geology student asked: do you understand why it is normal?" (first author, field notes). Despite the support given in the geology apprenticeship, participants revealed conceptual difficulties, especially related to the number of new concepts during the early stage of immersion: "I asked them if they were enjoying the experience and João stated-there are so many concepts!" (first author, field notes). These difficulties remained throughout the apprenticeship. Therefore, in the final interview both preservice teachers continued to reference them: "Difficulties, well, I think the only one I can mention is not having enough knowledge about those geological concepts" (Helena, FI) and "I think the biggest difficulty was really the appropriation of the content knowledge" (João, FI).

Epistemic difficulties were also reported in the malaria apprenticeship, although with less emphasis. According to the participants, they "didn't understand very well those scientific names and also what the drugs were going to do within the mosquitoes" (Leonor, FI). Despite these conceptual problems, the participants did not reveal difficulties clarifying generally the specific objectives underlying the study.

Regarding the data analysis, all preservice teachers participated only in the qualitative analysis performed during the experiments. Although the data underwent a subsequent quantitative analysis, the participants did not cooperate in this process.

Despite the low epistemic involvement of all participants, Helena and João had the opportunity to observe the discussions between the geology students and the scientist. Furthermore, the subject under study and how the scientist contextualized it highlighted contemporary polemics and controversies in the field that helped to illustrate NOS. The scientist, besides giving his opinions, was sensitive enough to explain other points of view of the scientific community even when they did not support his beliefs. This was not the case in the malaria apprenticeship because the number of interactions between the research elements was very low. 


\section{Methodological involvement}

In the geology apprenticeship, Helena and João participated actively in the different procedures associated with the preparation/storage of materials and experience assembly. In addition, some aspects of the initial design were modified with the future teachers' collaboration. These changes were made because of problems that had arisen during the preparation and assembly of the experiments. They also participated actively in the collection of data obtained using photographs, at regular intervals, during strata deformation and after deformation and wetting of the model.

Participants' role in the malaria apprenticeship was also not restricted to observation, as Carla and Leonor collaborated actively in different procedures. During data collection, the scientist or the doctoral student illustrated all of the different techniques (blood smear, drug inoculation, dissection of mosquito stomach, etc.) and, when possible, asked the students to reproduce them. Besides data collection, participants also helped in regular routines of the biotherium. In this setting, many methodological difficulties were reported by the participants, especially related to the manipulation of animals and blood.

\section{Views of NOS}

This section presents preservice teachers' views of each NOS aspect before, during, and after the program and the factors invoked by the participants in their change (see Table 3 ). After the apprenticeship but before the seminars, almost all participants indicated that they agreed with their initial answers. Only in a few cases did they write a new answer, but even then it was categorized at the same level of understanding.

\section{Social and cultural embeddedness of scientific knowledge}

In the beginning, Helena had a naive view of scientific activity because for her "science should be neutral" (Q1fu). The answers given by the other participants showed a much more contextualized view. However, when we analyzed the examples mentioned by these participants, it appeared that the influences were more relevant in the selection of a research theme than in the way those themes would be investigated, which showed a partially informed view .

In the seminar, hearing the answers given by all participants to Q1 helped Helena to realize that she had a different perspective regarding this theme:

Table 3. Changes in views of nature of science.

\begin{tabular}{|c|c|c|c|c|c|c|c|c|c|c|c|c|}
\hline \multirow[b]{3}{*}{ Aspect } & \multicolumn{6}{|c|}{ Geology } & \multicolumn{6}{|c|}{ Biology } \\
\hline & \multicolumn{3}{|c|}{ Helena } & \multicolumn{3}{|c|}{ João } & \multicolumn{3}{|c|}{ Leonor } & \multicolumn{3}{|c|}{ Carla } \\
\hline & Pre $^{a}$ & Post & Source ${ }^{b}$ & Pre & Post & Source & Pre & Post & Source & Pre & Post & Source \\
\hline Social and cultural & -- & - & $\mathrm{SA}_{\mathrm{g}}$ & + & + & $S$ & + & ++ & $S A_{b}$ & + & + & $S$ \\
\hline Empirical & - & ++ & $S A_{g}$ & - & + & $S A_{g}$ & + & ++ & $S A_{b}$ & - & + & $S$ \\
\hline Theory laden & - & ++ & $A_{g}^{g}$ & - & ++ & $s^{9}$ & + & + & $\mathrm{SA}_{\mathrm{g}}$ & -- & + & $S$ \\
\hline Creative & ++ & ++ & $\mathrm{SA}_{\mathrm{g}}$ & - & + & $A_{g}$ & ++ & ++ & $\mathrm{SA}_{\mathrm{g}}$ & - & + & $S$ \\
\hline Tentative & - & ++ & $\mathrm{SA}_{\mathrm{g}}$ & + & ++ & $\mathrm{SA}_{\mathrm{g}}$ & + & ++ & $\mathrm{SA}_{\mathrm{g}}$ & - & + & $S$ \\
\hline Theories and laws & -- & ++ & $\mathrm{S}^{9}$ & - & - & $0^{9}$ & -- & ++ & $S^{9}$ & -- & - & $S$ \\
\hline Total + or ++ & 1 & 5 & & 2 & 5 & & 5 & 6 & & 1 & 5 & \\
\hline
\end{tabular}

$\mathrm{a}_{-}-$= naive; - = limited; + = partially informed; ++ = informed. ${ }^{\mathrm{b}} \mathrm{S}=$ seminar; $\mathrm{A}_{\mathrm{g}}=$ geology apprenticeship; $\mathrm{A}_{b}=$ biology apprenticeship; $\mathrm{O}=$ other source. 
It is fun to read opinions different from mine ... and they are perfectly valid ... she says that if I am interested about a certain topic that's what I'm going to study ... so, maybe in that sense, science is conditioned by interests. (Helena, Seminar 2 [S2])

After this, Helena was able to invoke memories of the scientific apprenticeship that contradicted, at least partially, her initial idea: "Frederico said ... if our study helps to find oil, you have money, if not, it's not worth" (S2).

The use of animals in scientific research was also a topic discussed in one seminar, mainly by Leonor and Carla. In the beginning, Carla indicated that "scientists can have access to all methods and techniques that exist around the world, but they choose what they want" (S2). Leonor partially agreed with this view. For her, scientists can choose techniques, and in order to highlight this fact she shared information reported by a researcher in the apprenticeship: "One of the scientists said that although the technique didn't cause suffering to the animal ... she was afraid and did not use it" (S2). However, she also believed that scientists do not have access to all techniques for financial reasons.

At the end of the program, Helena and Leonor showed improvements in their understanding of the cultural and social influences on scientific enterprise. Helena's view improved from naive to limited, mainly because she started to recognize that science is not an autonomous activity, especially because of the funding issues that were discussed in the seminar and with the scientist. According to Leonor, the development of an informed view was a consequence, on the one hand, of the experiences that arise from the apprenticeship and, on the other hand, of the reflections in the seminars. These moments helped her analyze the social and cultural influences on how science is practiced: "I think that everyone is against the use of animals to do experiences, but in mice nobody cares ... if they were dogs ... so it reflects social and cultural values" (Leonor, Q3). Carla's and João's partially informed views remained largely unchanged over the course of the program. For these participants the seminars were the component of the program in which this dimension of science became more audible.

\section{Empirical nature}

Before the program, Helena, João, and Carla presented limited views regarding this NOS dimension because, according to them, the development of scientific knowledge focused solely on direct evidence obtained from experiments. Leonor showed partially informed conceptions because she recognized that scientific knowledge is not derived only and directly from these empirical data.

The fact that science is based on and derived from observation from which interpretations are made was an aspect evident in the seminars. According to the participants in the apprenticeships the scientists were trying to collect data to develop explanations, and this was an important characteristic of science. They also highlighted the importance, even when working with models, of confronting the results with nature: "Nature isn't wrong, ultimately, they have to go to the field to see if it is really possible to have happened" (Helena, Seminar 4 [S4]).

In the end, Helena and Leonor expressed informed views about the empirical nature of scientific knowledge, whereas João and Carla showed partially informed views. Except for 
Carla, for whom seminars were the main source for the change in views, all participants indicated the seminars as well as the apprenticeship.

The initial terms used by Helena, like "facts" and "proofs," were replaced by others, like "arguments," and her discourse revealed that although scientific knowledge is derived from observation, these observations are not theory and value free. According to Leonor, data do not speak for themselves, and therefore her discourse during the final interview focused on the importance of the argumentation "as long as I justify it, and convince them, in this case, persuade them" (Q3). Although João recognized that "each people will interpret data in a different way" (Q3), this aspect was underrated by the participant because for her scientists are "limited by the data, they can interpret based on them, but they cannot extrapolate from them" (Q3). Although Carla did not emphasize the role of prior knowledge and assumptions in the development of scientific knowledge, she stated that "the data is not fixed, it also rises other questions and doubts" (Q3), which denoted that she no longer held the naive view she had at the beginning of the program.

\section{Theory-laden nature of scientific knowledge}

Initially Helena and João had limited views about the role of subjectivity and theory in the development of scientific knowledge. For João, the coexistence of different explanatory hypotheses for the dinosaurs' extinction was due mainly to the quality of the data obtained. A similar opinion was expressed by Helena when she mentioned that "the more data we have available, the more narrow the conclusion will be" (Q1fu). Carla, when confronted with the same question, wrote, "I accept these theories, however I cannot explain how scientists arrived at these conclusions" (Q1), which indicated a naive view. Only Leonor recognized the role that beliefs and assumptions play in the formulation and supporting evidence: "It is possible to draw different conclusions due to life experience and to the previously experimentation made by scientists" (Q1). However, for this participant subjectivity was mainly related to personal subjectivity, which reflected a partially informed view of this NOS dimension.

During the seminars, the theory-laden nature of scientific knowledge was mainly illustrated through the geology apprenticeship. The epistemic involvement made by Frederico regarding the existence of different hypotheses to explain certain geological phenomena was the starting point for Helena to reconsider her initial views:

Frederico have published something that is completely the opposite of what so far was accepted ... and now we have two different views of the same thing, we have the same data, the same evidence, but scientists with different theories. (S4)

This discussion was mainly constructed between Helena and João. Carla sometimes agreed with the ideas conveyed by colleagues. For example, she initially agreed with the importance of "mentalities" to justify changes in scientific knowledge but after an explicit request to illustrate this importance remained silent. Furthermore, after the statement of a colleague indicating possible change in the scientific knowledge with the same data, the admiration of Carla became evident: "But how?" (Carla, Seminar 5 [S5]).

During the seminars Helena also reflected about the aim of observations: "These two scientists ... were facing a real situation ... and clearly were watching different things, because they have completely different opinions, so maybe we observe and analyze things 
differently" (S4). These experiences were partly at odds with Helena's view of what science is and how it should be practiced. After the explanation of these situations, and when asked whether she would like observation to be completely objective or whether it is something that we make an effort to accomplish, Helena returned to her initial perspective: "I think so, that observation should be neutral if it is, in all cases, I do not know" (S4). After this conflict between what Helena saw and heard and her beliefs, she invoked more memories of the apprenticeship in order to develop her argumentation. The feedback of João was important in fostering Helena's reflection and analysis: "But isn't! It is difficult to be neutral, it is very difficult ... there is always subjectivity" (S4).

At the conclusion of the program, Helena and João displayed informed understandings of this aspect. Helena recalled several episodes experienced in the apprenticeship to justify why she no longer agreed with the initial answers. For example, to justify the existence of different hypotheses for the dinosaurs' extinction, Helena quickly established a parallelism with Frederico's work:

Because they were opposing conclusions, Frederico thinks that a new subduction zone is being formed and the other scientist says no, that nothing is moving ... and perhaps this happens due to the scientists' training experiences and the personal characteristics. (Helena, Q3)

João also started to value the "interpretation of the scientists ... what he has in mind or the way he looks at the data" (Q3). According to her, the seminars were crucial for the development of this new vision because of the existence of different opinions and the analysis of diverse situations.

Carla showed partially informed views because although she started to value the importance of subjectivity, this occurred mainly at the personal level: "People interpret things in different ways according to what they are, according to their personality" (Q3). In addition, she stated that "it is a hard thing to really be sure about what happened and therefore the coexistence of two hypothesis is possible" (Q3), which indicated that the nature of knowledge by itself and the moment when phenomena occurred were also plausible explanations for this scenario. According to this participant, the seminars were the most important moments that helped to change her opinion.

Leonor did not show improvements regarding this NOS aspect, maintaining her partially informed view. For her, the information shared by the participants who collaborated in the geology apprenticeship and the discussion in the seminars were the aspects of the program that contributed to the reinforcement of this idea.

\section{Creative and imaginative nature of scientific knowledge}

Helena and Leonor had informed conceptions of the role of creativity and imagination in the development of scientific knowledge because they recognized its importance in all phases of scientific research and were able to use these terms to describe the ability to construct scientific explanations. According to Leonor it allowed "us not to be limited to what we have in our hands, with what we can collect or see, and to think and imagine beyond what is there" (Q1fu). The remaining participants evidenced limited conceptions of this NOS dimension because they believed that these characteristics were more important during pre-data collection: "I think in the planning ... when you are thinking about 
how to collect the data" (João, Q1fu) and "Their imagination will arise during the research planning" (Carla, Q1).

Regarding this NOS dimension the geological apprenticeship was the apprenticeship more mentioned and analyzed during the seminars, especially an episode related to different tectonic interpretations of a Mediterranean area.

After the program, Helena and Leonor continued to show informed views about the importance of creativity and imagination in the construction of scientific knowledge. For Helena, the apprenticeship and the seminars were decisive in reinforcing this idea: "Frederico transmitted this idea, who thinks what no one else thinks, is the one that really puts science to move, and also the conversation that we had about that here" (Q3). For Leonor, the information shared by the participants who collaborated with Frederico during the seminars was the aspect that most influenced the reinforcement of her idea: "I didn't see a great imagination in our apprenticeship ... I think that this is more evident with the Frederico" (Q3).

Carla's and João's views improved after the program from limited to partially informed because they both started to recognize that scientists use creativity and imagination at any stage of an investigation. According to Carla, the seminars were the moments that contributed the most to her rethinking this NOS aspect, and for João the work with Frederico helped her to construct this idea.

\section{Tentative nature of scientific knowledge}

In the beginning, Helena and Carla had limited views regarding the tentative nature of scientific knowledge. Helena recognized the possibility that some theories undergo changes over time due to new findings and advances in technology, especially in areas where we do not know everything:

There are theories that yes, we come to that conclusion, and it is ready ... but ... in that part of the astronomy, of existing life on other planets, is in this sense that I say that science is always evolving. (Q1fu)

A similar idea was shared by Carla when she reported that the tentative nature of scientific knowledge was a consequence of new "means/materials that allow us to have another look at a certain theory" (Q1). These ideas denoted a superficial understanding of this NOS dimension because they failed to recognize the possibility of changing scientific knowledge through a reinterpretation of the same data.

Leonor and João, however, expressed partially informed views regarding this NOS aspect because they did not explicitly state that theory changes solely because of new technology or knowledge. For example, for João "science is always evolving over time through the development of technology and the development of attitudes" (Q1), whereas for Leonor "times change and that also change the people and scientists mentality" (Q1). Although they both mentioned changes in scientists' attitudes and mentality through time, they were not able to further explore this idea and its consequences in data reinterpretation, and this was the main reason the participants' views were not considered to be informed.

During the seminars, the tentative nature of scientific knowledge was a very visible aspect of João's discourse. Even with the examples provided by Helena, João continued to defend and justify the idea that science is tentative: "What you can say is, according to the 
information we have now, according to what we now know this is right, does not mean that at a long-term" (S5). After this debate, some situations of the geological apprenticeship were reinterpreted by Helena in a slightly different way, showing a more informed view of this NOS feature: "Is just to test the hypothesis, tests the hypothesis and you passed to admit if this hypothesis could have happened, or not, that does not mean it has happened it that way" (S5).

The fact that science is subject to change in the light of new evidence was recognized by all of the participants. However, after reading the answer given to Q1, the possibility of news interpretations of existing evidence was also discussed.

At the end of the program Helena, João, and Leonor expressed informed views about the tentative nature of NOS knowledge. Carla's views showed moderate developments from limited to partially informed.

This aspect became for Helena a fundamental feature of science, and therefore when confronted with her initial answer to the question "What is, in your view, science?" Helena started to enhance the controversies inherent in the development of scientific knowledge: "Here, I talk a lot about exact answers, perhaps I would change this ... I'd say that tries to find the closest answer ... but the scientific community knows that nothing is exact" (Q3).

According to Helena, the discussions promoted in the seminars were very important to redefining her ideas because they "complement what we talked about and watched with Frederico ... and also because we were at confront with each other" (Q3). Regarding the apprenticeship Helena identified the following episode as the most important:

He [Frederico] said ... that it had been formed in a certain way, and the other [scientist] said it was something completely different, and yet we are talking about two people who do science for a long time and they were looking for the same answer in different ways. (Q3)

This episode, because it highlights the role of discussion and subjectivity in the construction of scientific knowledge, proved to be a critical incident on which various analyses, discussions, and reconceptualizations were based.

After the program, Leonor recognized that to change a theory "I can try to find new data or I can use the data that already exist and have a new interpretation, as long as I justify it" (Q3). In her opinion, the seminar was the component of the Live Science program that contributed most to reinforcing this idea because it allowed her to understand what happened in "Helena and João's apprenticeship" (Q3).

According to João, the apprenticeship helped to reinforce her initial view because the researcher with whom she collaborated had formulated a different hypothesis from the currently accepted one about the succession of geological phenomena in a given region. For João these scientific controversies emphasized the tentative nature of scientific knowledge and corresponded to a positive side of science because "it is good that someone is thinking 'the opposite,' otherwise, nothing would ever change” (Q3).

Carla also showed developments in her view of the tentativeness of science from limited to partially informed because she no longer emphasized that changes occur only through new data. According to this participant, the discussions held in the seminars contributed to the strengthening of her initial ideas. 


\section{Functions of and relationships between scientific theories and laws}

Helena, Leonor, and Carla expressed naive views about the difference and relationship between scientific theories and laws. The definitions provided by these participants were inaccurate because the difference between these two types of scientific knowledge was only based on the level of "proof"-laws are proven to be true and theories can change. Moreover, Leonor and Carla believed that theories will become laws when "proven" true, failing to recognize that theories and laws are different types of scientific knowledge. João was the only participant with limited views regarding this NOS feature, mainly because she did not base her definition explicitly on the level of "proof." Yet she failed to fully understand the difference between these two concepts. Furthermore, for João, laws and theories were "different things ... does not make sense to put one in front of the other" (Q1).

During the program, especially during the first seminars, it became clear that the participants used the word theory with different meanings, misleading and conflating the technical and everyday meanings of the word. Therefore, seminar transcripts in which the word theory had been used were examined during the fifth seminar. The context of each example and the different participants' knowledge helped determine which meaning was intended (sometimes they used the word theory when they really meant hypothesis, a hunch or a belief) and differentiate the technical and everyday meanings of the word. Even when João started to emphasize that a theory needs to be well supported and widely accepted, the participants showed difficulty differentiating hypothesis and theory. Moreover, Leonor felt the need to differentiate theories according to the contemporaneity of the phenomena that they seek to explain: "Regarding plate tectonics theory, we have earthquakes that prove that probably happen because of the theory, isn't it? While the Big Bang was something that happened long ago and supposedly we can't see it now" (S5). João also stated that "I think the law explains, I think the law has more to do with logic, while the theory ... this is so complicated" (S5). However, after analyzing a well-known law (Newton's law), this was deconstructed.

João's participation was especially important in countering the hierarchical relationship that some participants had as regards the relation between theories and laws: "And why not from a law to a theory? Maybe it even makes more sense ... I think the problem is that we want to put levels, and we shouldn't" (S5). Regarding this discussion Helena clearly stated that she was having difficulties participating and understanding the difference between these two scientific constructs. Probably the fact that she was unable to find apprenticeship examples to rethink about these aspects contributed to this feeling: "I'm confused! ... So how a law does arises? The law comes when I know something happens but do not know how to explain?" (S5). The same happened with Leonor. According to this participant, the theme under analysis was difficult and complex. Furthermore, she mentioned that the discussion had been an important contribution to her rethinking some of her initial ideas: "I am reflecting, yes, I think so, I agree ... it what you were saying ... we cannot rank and we were trying to do that" (S5).

At the end of the Live Science program, Helena and Leonor showed informed views about the difference between theories and laws, whereas João and Carla expressed limited views.

Helena reflected a deeper understanding of theories and laws, as the degree of (un) certainty was no longer seen as the differentiating aspect between them. She indicated that a theory "seeks to explain a possible phenomenon, how it may have happened, whereas a 
law is something that tells us that a certain thing will happen that way" (Q3), which illustrated that theories and laws were regarded as different types of knowledge with no hierarchical relationship between them. According to this participant, the discussions promoted in the seminars helped her to clarify these concepts because "with Frederico we didn't talk much about these issues" (Q3).

The functions and relationships between theories and laws were also described by Leonor more in line with contemporary views. It became more evident that for her theories are "something that are accepted but you cannot ... so I cannot prove the Big Bang" (Q3). She also stated that laws are "possible to be observed, supposedly found while the theory is one thing that is supposed to" (Q3).

Carla also showed some developments because she was able to give descriptions of theories and laws that were not based on the level of proof, but even so she revealed difficulties understanding the difference between the two. Although she indicated that a law can also change she immediately stated that "I think maybe the laws are harder to refute" (Q3). Again, Carla invoked the seminars as the part of the Live Science program that contributed to the reconstruction of this opinion.

João continued to agree with what she had written initially regarding the difference and relation between theory and law but added that "I think a law affects a scientific theory ... the construction of a theory" (Q3). Although she remembered the discussions about this topic in her opinion, the initial training in the School of Education was more important to the development of these conceptions.

\section{Discussion and implications}

In this section, and based on the in-depth study of the experiences and learning resulting from the Live Science program, we try to discuss and respond in a systematic way to the three research questions that guided the study.

\section{What are the features of the research experiences offered in the Live Science program?}

The scientific research experiences offered in the Live Science program revealed differences but also commonalties. In both apprenticeships, the participants were involved, according to Hughes et al.'s (2012) categorization, in actual research because they had the opportunity to collaborate on a project conducted by the research team.

Regarding the affective-relational involvement of participants, it was found that the accessibility and friendliness of the members of the research team, as well as the interest they demonstrated in the collaboration of the future teachers in the investigation, were the features most appreciated by participants and the features that contributed to building a pleasant environment. Therefore, and as in other studies (Thiry \& Laursen, 2011; Westerlund et al., 2002), scientist behavior and attitudes were crucial in building a trusting and collegial relationship, which in time helped participants to feel more comfortable.

Although preservice teachers did not, as expected, become full participants in the scientific community, the technical support given by the research group allowed participants to gain methodological proficiency and to conduct different data collection 
procedures. Therefore, our results indicate that methodological involvement is possible, even in a short-term apprenticeship.

However, despite the authenticity of the context, participants' epistemic involvement was peripheral, as the role play by them was restricted to observing, questioning, and conducting procedures. Similar results have been reported in other studies being the temporal extension of participants' immersion, in real science context, one of the main factors for the peripheral involvement (Bell et al., 2003; Westerlund et al., 2002). Moreover, in our study, a lack of conceptual knowledge was one of the factors pointed to by the participants to justify this level of participation. Our participants had, because of the generalist model of elementary teacher preparation adopted in Portugal, little formal training in science. Accordingly, the possible disparity between the conceptual effort required and participants' prior knowledge may be an explanatory factor. Given the time limitations of these types of programs and the low level of content knowledge held by preservice elementary teachers, we believe that epistemic involvement is probably very difficult to achieve with these participants, a conclusion that is also corroborated by other authors (Feldman, Divoll, \& Rogan-Klyve, 2013).

It is important to note that despite the similarities, differences were also observed between the two real science contexts offered in the Live Science program. Research in the field of geology was characterized as a richer experience because of the frequency and nature of support provided as well as the high number of relationships established within the research team and the nature of these relations. Here, although the preservice teachers did not participate directly and frequently in the epistemic activities, they had the opportunity to observe them. Because many apprenticeship programs use different settings for the immersion of participants, our results reinforce the importance of characterizing the singular aspects of each setting to achieve a deeper analysis of the impact of these programs instead of adopting a holistic approach (Burgin, Sadler, \& Koroly, 2012; Sadler et al., 2010).

In summary, several pieces of evidence indicate that the future teachers were legitimate peripheral participants because they interacted with different members of the research team and had access to the main research activities, tools, and resources of the practice (Lave \& Wenger, 1991). However, sharing stories and arguing about the most problematic and difficult features of scientific activity on top of diverse and rich group relationships, aspects that support learning in authentic contexts (Lave \& Wenger, 1991), were more noticeable in the geology group.

\section{How do preservice elementary teachers' views of NOS change during the Live Science program?}

Regarding NOS, our participants' initial views were similar to the ones reported in many investigations (Abd-El-Khalick \& Akerson, 2004; Akerson et al., 2000), as all four participants held inadequate understandings of different NOS features. This result suggests that the preservice teacher training program these participants had was not effective in terms of NOS knowledge. In addition, this reality also reinforces the relevance of adopting and analyzing different strategies during these training programs.

Like in other studies (Bell et al., 2003; Schwartz et al., 2010) we also found that even after their immersion in real science contexts, participants maintained their initial 
conceptions of NOS. In addition, each participant interpreted the apprenticeship differently, which shows the influence that initial conceptions have on the ability to interpret a given reality. As in a study developed by Rahm, Miller, Hartley, and Moore (2003) the initial conceptions of our participants "were more powerful than the experiences they had in the field or ... dialogue with the scientist" (p. 749). Substantial gains in NOS understandings were only detected during and after the seminars, which suggests that the explicit-reflective component of the program was the main cause of these improvements.

\section{What features of the program, if any, are more relevant for fostering NOS understandings?}

Our results reinforce the idea that the implicit approach, which is based on the assumption that by "doing science" (future) teachers begin to understand NOS, probably is not enough (Khishfe \& Abd-El-Khalick, 2002; Schwartz et al., 2010).

Although other studies have also adopted NOS explicit approaches, the strategies used have not always been the same. For example, Schwartz et al. (2010) selected different NOS activities from the literature and also discussed articles about NOS perspectives and common myths about science with some of the teachers involved in their study. These sessions were done weekly and alongside the teachers' immersion in an apprenticeship. However, as it has been documented that some of these activities by themselves impact on participants' NOS views (Akerson et al., 2000; Ozgelen, Yilmaz-Tuzun, \& Hanuscin, 2012), we believe that the role of the apprenticeship was not fully analyzed in these studies. In our study the explicit and reflective components were totally grounded in the experience lived by the participants, and even without extra activities and materials our model was effective in enabling improvements in participants' views of NOS.

It is also important to stress that these developments in NOS understandings occurred despite low epistemic involvement in the apprenticeships. These data are in accordance with other studies that have also found an impact on participants' conceptions of NOS with this type of epistemic involvement (Schwartz et al., 2004) and also a study conducted by Burgin et al. (2012), who found "that individuals within the high NOS group demonstrated variable epistemic involvement. This pattern suggested that epistemic involvement was not necessarily associated with the NOS variable" (p. 460). This feature is quite important because, as we mentioned earlier in this section, epistemic involvement is probably too difficult for short-term apprenticeships.

Another interesting finding is that the geology apprenticeship, in which the epistemic aspects of the research group were more visible, was the most invoked context for reflection. Consequently, not all scientific inquiry contexts were equally good contexts for reflection. This aspect is, in our opinion, extremely important because it suggests that some NOS aspects become less visible and audible in certain research contexts. In our study, the structure/interactions of the research group, the type and duration of the support given by the team, and the very nature of the research field were the aspects most related to the richness of the scientific experience .

The importance of the structure/interactions of the research group has also been reported in other studies (Burgin et al., 2012; Feldman, Divoll, \& Rogan-Klyve, 2009; Feldman et al., 2013). Feldman et al. $(2009,2013)$ analyzed graduate and undergraduate 
students during their participation in research activities and found that research groups were structured in two different ways-loosely organized and tightly organized-the latter being better for enhancing students' learning. Our study corroborates these findings as the geological research group, a tight group, enabled participants to interact more with other members of the group, who had different methodological and conceptual proficiencies and who, besides the scientist, also assumed a mentor role. Moreover, it seems that the organization of a group is closely correlated with the potentiality of enabling participants to observe the epistemic community within the research group. The conception of epistemic demand, elaborated by Ryder and Leach (1999), is relevant to further understanding the relevance of the nature of the research field. Frederico's line of research was characterized by competing hypotheses that were dissonant with the NOS views that participants had and that were repeatedly described by the scientist. This aspect was also identified in the work conducted by Bell et al. (2003), as the only participant involved in an implicit NOS apprenticeship who made improvements in terms of NOS understandings was one who was working with a scientist in a field with the same characteristics.

The type and duration of the support given by the team, the last aspect that we found to be related to the richness of the scientific experience, is closely associated with the other two aspects mentioned. Even in disciplines in which different competing hypotheses are present, the scientist plays an important role in clarifying these scientific controversies. Without this illustration the reflection in the seminars would be necessarily poorer.

Given the above discussion, it could be expected that the participants who collaborated in the geology apprenticeship would be the ones with greater improvement. However, this is not the case, and the explanation is quite obvious. The seminars helped the participants to gain insight into different scientific realities through the descriptions of the other apprenticeship. This aspect was very evident in Leonor's developments, as they were grounded in episodes of the geology apprenticeship. This characteristic of our program diluted the relation between the participants' NOS improvements and the research setting in which they were immersed. Carla, however, had more difficulties establishing a deeper connection with specific critical incidents of the research settings and, at the same time, made more modest improvements.

The developments detected also differed between Helena and João, the other two participants who collaborated in the same apprenticeship. Helena was the one who revealed more improvements. Different explanations can account for this development. First, she was the participant who entered the program with more naive views and consequently with more possibilities to improve. Second, she was a participant who revealed a reflexive posture and positive attitudes toward science throughout the program. João also collaborated in the same apprenticeship, and although her NOS understandings improved, the improvements were more moderate. In this case other factors played an important role, in particular the preexisting beliefs and educational experience of the participant. That aspect is quite evident by the sources she mentioned to explain her final understandings of NOS.

Therefore, it seems that a rich scientific research context combined with guided moments to enhance reflections on that context is an extremely important factor that contributed to fostering participants' views about NOS. These conclusions are supported by the fact that the NOS features that revealed overall more developments were the ones 
that were visible in the scientific research experience. However, other factors also play an important role in this process, namely, personal factors such as reflection perspective, previous beliefs, and interest in science.

Consequently, our study suggests that NOS enhancements are possible regardless of the level of epistemic involvement but not the epistemic demand of the apprenticeship. An important consequence of this interpretation is the potential benefit of including apprenticeships with different types of epistemic demands in order to cover a higher range of NOS features. This also highlights the importance of characterizing the depth of the apprenticeship during the investigation in order to fully understand the process that triggers improvements in NOS views. Another implication of our study is that in future research experiences, more attention should be paid to the selection of apprenticeships. Tightly organized research teams capable of giving ample support to preservice teachers working in research fields in which the participants' conceptions can be confronted should be selected in order to improve the impact of this type of programs.

\section{ORCID}

Bianor Valente (1) http://orcid.org/0000-0001-6541-8000

Paulo Maurício (1) http://orcid.org/0000-0003-3321-9108

Cláudia Faria (iD http://orcid.org/0000-0003-1278-8061

\section{References}

Abd-El-Khalick, F. (2012). Examining the sources for our understandings about science: Enduring conflations and critical issues in research on nature of science in science education. International Journal of Science Education, 34(3), 353-374. doi:10.1080/09500693.2011.629013

Abd-El-Khalick, F., \& Akerson, V. L. (2004). Learning as conceptual change: Factors mediating the development of preservice elementary teachers' views of nature of science. Science Education, 88(5), 785-810. doi:10.1002/sce.10143

Abd-El-Khalick, F., \& Lederman, N. G. (2000). The influence of history of science courses on students' views of nature of science. Journal of Research in Science Teaching, 37(10), 1057-1095. doi:10.1002/1098-2736(200012)37:10<1057::AID-TEA3>3.0.CO;2-C

Abell, S. K., \& Smith, D. C. (1994). What is science? Preservice elementary teachers' conceptions of the nature of science. International Journal of Science Education, 16(4), 475-487. doi:10.1080/ 0950069940160407

Akerson, V. L., Abd-El-Khalick, F., \& Lederman, N. G. (2000). Influence of a reflective explicit activity-based approach on elementary teachers' conceptions of nature of science. Journal of Research in Science Teaching, 37(4), 295-317. doi:10.1002/(SICI)1098-2736(200004)37:4<295:: AID-TEA2>3.0.CO;2-2

Allchin, D. (2011). Evaluating knowledge of the nature of (whole) science. Science Education, 95(3), 518-542. doi:10.1002/sce.20432

Allchin, D. (2013). Teaching the nature of science: Perspectives and resources. Saint Paul, MN: SHiPS Education Press.

American Association for the Advancement of Science. (1993). Benchmarks for science literacy: A Project 2061 report. New York, NY: Oxford University Press.

Bell, R. L., Blair, L. M., Crawford, B. A., \& Lederman, N. G. (2003). Just do it? Impact of a science apprenticeship program on high school students' understandings of the nature of science and scientific inquiry. Journal of Research in Science Teaching, 40(5), 487-509. doi:10.1002/(ISSN)1098-2736 
Bell, R. L., Lederman, N. G., \& Abd-El-Khalick, F. (2000). Developing and acting upon one's conception of the nature of science: A follow-up study. Journal of Research in Science Teaching, 37(6), 563-581. doi:10.1002/1098-2736(200008)37:6<563::AID-TEA4>3.0.CO;2-N

Brown, S., \& Melear, C. (2007). Preservice teachers' research experiences in scientists' laboratories. Journal of Science Teacher Education, 18(4), 573-597. doi:10.1007/s10972-007-9044-9

Burgin, S., Sadler, T., \& Koroly, M. (2012). High school student participation in scientific research apprenticeships: Variation in and relationships among student experiences and outcomes. Research in Science Education, 42(3), 439-467. doi:10.1007/s11165-010-9205-2

Bybee, R. (1997). Achieving scientific literacy: From purposes to practices. Portsmouth, NH: Heinemann.

Clough, M. (2006). Learners' responses to the demands of conceptual change: Considerations for effective nature of science instruction. Science \& Education, 15(5), 463-494. doi:10.1007/s11191005-4846-7

Corbin, J., \& Strauss, A. (2008). Basics of qualitative research: Techniques and procedures for developing grounded theory. Thousand Oaks, CA: Sage.

Creswell, J. W. (2007). Qualitative inquiry and research design: Choosing among five traditions. London, UK: Sage.

Denzin, N. K., \& Lincoln, Y. S. (1994). Introduction: Entering the field of qualitative research. In N. K. Denzin \& Y. S. Lincoln (Eds.), Handbook of qualitative research (pp. 1-17). London, UK: Sage.

Dresner, M., \& Worley, E. (2006). Teacher research experiences, partnerships with scientists, and teacher networks sustaining factors from professional development. Journal of Science Teacher Education, 17(1), 1-14. doi:10.1007/s10972-005-9000-5

Feldman, A., Divoll, K., \& Rogan-Klyve, A. (2009). Research education of new scientists: Implications for science teacher education. Journal of Research in Science Teaching, 46(4), 442459. doi:10.1002/tea.20285

Feldman, A., Divoll, K., \& Rogan-Klyve, A. (2013). Becoming researchers: The participation of undergraduate and graduate students in scientific research groups. Science Education, 97(2), 218243. doi:10.1002/sce. 21051

Hodson, D. (2008). Towards scientific literacy: A teachers' guide to the history, philosophy and sociology of science. Rotterdam, The Netherlands: Sense.

Hodson, D. (2009). Teaching and learning about science: Language, theories, methods, history, traditions and values. Rotterdam, The Netherlands: Sense.

Hodson, D. (2014). Nature of science in the science curriculum: Origin, development, implications and shifting emphases. In M. R. Matthews (Ed.), International Handbook of Research in History, Philosophy and Science Teaching (pp. 911-970). Dordrecht, The Netherlands: Springer. doi:10.1007/978-94-007-7654-8_28

Hughes, R., Molyneaux, K., \& Dixon, P. (2012). The role of scientist mentors on teachers' perceptions of the community of science during a summer research experience. Research in Science Education, 42(5), 915-941. doi:10.1007/s11165-011-9231-8

Irzik, G., \& Nola, R. (2011). A family resemblance approach to the nature of science for science education. Science \& Education, 20(7-8), 591-607. doi:10.1007/s11191-010-9293-4

Kampourakis, K. (2016). The "general aspects" conceptualization as a pragmatic and effective means to introducing students to nature of science. Journal of Research in Science Teaching, 53(5), 667682. doi:10.1002/tea.21305

Khishfe, R., \& Abd-El-Khalick, F. (2002). Influence of explicit and reflective versus implicit inquiryoriented instruction on sixth graders' views of nature of science. Journal of Research in Science Teaching, 39(7), 551-578. doi:10.1002/(ISSN)1098-2736

Lave, J., \& Wenger, E. (1991). Situated learning: Legitimate peripheral participation. Cambridge, UK: Cambridge University Press.

Lederman, N. G. (2004). Syntax of nature of science within inquiry and science instruction. In L. Flick \& N. Lederman (Eds.), Scientific inquiry and nature of science (Vol. 25, pp. 301-317). Dordrecht, The Netherlands: Springer. doi:10.1007/978-1-4020-5814-1_14 
Lederman, N. G. (2007). Nature of science: Past, present and future. In S. K. Abell \& N. G. Lederman (Eds.), Handbook of research on science education (pp. 831-879). Mahwah, NJ: Erlbaum.

Lederman, N. G., Abd-El-Khalick, F., Bell, R. L., \& Schwartz, R. (2002). Views of nature of science questionnaire: Toward valid and meaningful assessment of learners' conceptions of nature of science. Journal of Research in Science Teaching, 39(6), 497-521. doi:10.1002/tea.10034

Lederman, N. G., \& Lederman, J. S. (2014). Research on teaching and learning of nature of science. In N. G. Lederman \& S. K. Abell (Eds.), Handbook of research on science education (Vol. 2, pp. 600-620). New York, NY: Routledge.

Liang, L. L., Chen, S., Chen, X., Kaya, O. N., Adams, A. D., Macklin, M., \& Ebenezer, J. (2009). Preservice teachers' views about nature of scientific knowledge development: An international collaborative study. International Journal of Science and Mathematics Education, 7(5), 987-1012. doi:10.1007/s10763-008-9140-0

Matthews, M. R. (2012). Changing the focus: From nature of science (NOS) to features of science (FOS). In M. S. Khine (Ed.), Advances in nature of science research (pp. 3-26). Dordrecht, The Netherlands: Springer. doi:10.1007/978-94-007-2457-0_1

McComas, W., Clough, M., \& Almazroa, H. (1998). The role and character of the nature of science in science education. In W. McComas (Ed.), The nature of science in science education (pp. 3-39). Dordrecht, The Netherlands: Springer. doi:10.1007/0-306-47215-5_1

McDonald, C. (2008). Exploring the influence of a science content course incorporating explicit nature of science and argumentation instruction on preservice primary teachers' views of nature of science. Brisbane, Australia: Queensland University of Technology.

Melear, C., Goodlaxson, J., Warne, T., \& Hickok, L. (2000). Teaching preservice science teachers how to do science: Responses to the research experience. Journal of Science Teacher Education, 11 (1), 77-90. doi:10.1023/A:1009479915967

Merriam, S. B. (1995). What can you tell from an $\mathrm{N}$ of 1 ? Issues of validity and reliability in qualitative research. PAACE Journal of Lifelong Learning, 4(1), 51-60.

Ministry of Education. (2007). The New Zealand curriculum. Wellington, New Zealand: Learning Media Limited.

Murcia, K., \& Schibeci, R. (1999). Primary student teachers' conceptions of the nature of science. International Journal of Science Education, 21(11), 1123-1140. doi:10.1080/ 095006999290101

National Research Council. (1996). National science education standards. Washington, DC: National Academies Press.

NGSS Lead States. (2013). Next generation science standards: For states, by states. Washington, DC: National Academies Press.

Ozgelen, S., Yilmaz-Tuzun, O., \& Hanuscin, D. L. (2012). Exploring the development of preservice science teachers' views on the nature of science in inquiry-based laboratory instruction. Research in Science Education, 43(4), 1-20. doi:10.1007/s11165-012-9321-2

Rahm, J., Miller, H. C., Hartley, L., \& Moore, J. C. (2003). The value of an emergent notion of authenticity: Examples from two student/teacher-scientist partnership programs. Journal of Research in Science Teaching, 40(8), 737-756. doi:10.1002/(ISSN)1098-2736

Raphael, J., Tobias, S., \& Greenberg, R. (1999). Research experience as a component of science and mathematics teacher preparation. Journal of Science Teacher Education, 10(2), 147-158. doi:10.1023/A:1009476025192

Ryder, J., \& Leach, J. (1999). University science students' experiences of investigative project work and their images of science. International Journal of Science Education, 21(9), 945-956. doi:10.1080/095006999290246

Sadler, T. D., Burgin, S., McKinney, L., \& Ponjuan, L. (2010). Learning science through research apprenticeships: A critical review of the literature. Journal of Research in Science Teaching, 47(3), 235-256. doi:10.1002/tea.20326

Schwartz, R. S., Lederman, N. G., \& Crawford, B. (2004). Developing views of nature of science in an authentic context: An explicit approach to bridging the gap between nature of science and scientific inquiry. Science Education, 88(4), 610-645. doi:10.1002/(ISSN)1098-237X 
Schwartz, R. S., Northcutt, C., Mesci, G., \& Stapleton, S. (2013). Science research to science teaching: Developing preservice teachers' knowledge and pedagogy for nature of science and inquiry. Retrieved from http://www.wmich.edu/cas/experts/docs/Schwartz_2013NARST_paper2.pdf

Schwartz, R. S., Westerlund, J., García, D., \& Taylor, T. (2010). The impact of full immersion scientific research experiences on teachers' views of the nature of science. Electronic Journal of Science Education, 14(1), 1-40.

Thiry, H., \& Laursen, S. (2011). The role of student-advisor interactions in apprenticing undergraduate researchers into a scientific community of practice. Journal of Science Education and Technology, 20(6), 771-784. doi:10.1007/s10956-010-9271-2

Varelas, M., House, R., \& Wenzel, S. (2005). Beginning teachers immersed into science: Scientist and science teacher identities. Science Education, 89(3), 492-516. doi:10.1002/(ISSN)1098-237X

Wahbeh, N., \& Abd-El-Khalick, F. (2013). Revisiting the translation of nature of science understandings into instructional practice: Teachers' nature of science pedagogical content knowledge. International Journal of Science Education, 36(3), 1-42. doi:10.1080/09500693.2013.786852

Wenger, E. (1998). Communities of practice: Learning, meaning, and identity. Cambridge, UK: Cambridge University Press.

Westerlund, J., García, D., Koke, J., Taylor, T., \& Mason, D. (2002). Summer scientific research for teachers: The experience and its effect. Journal of Science Teacher Education, 13(1), 63-83. doi:10.1023/A:1015133926799 